\title{
An Empirical Study on M\&A Performance: Evidence from Horizontal Mergers and Acquisitions in the United States
}

\author{
Jinling Jiang \\ School of Management, Jinan University, Guangzhou, China \\ Email: jalynn_jiang@163.com
}

How to cite this paper: Jiang, J.L. (2019) An Empirical Study on M\&A Performance: Evidence from Horizontal Mergers and Acquisitions in the United States. Open Journal of Business and Management, 7, 976-997.

https://doi.org/10.4236/ojbm.2019.72066

Received: March 25, 2019

Accepted: April 23, 2019

Published: April 26, 2019

Copyright $\odot 2019$ by author(s) and Scientific Research Publishing Inc. This work is licensed under the Creative Commons Attribution International License (CC BY 4.0).

http://creativecommons.org/licenses/by/4.0/

\begin{abstract}
Synergy theory holds that horizontal mergers and acquisitions (M\&A) are conducted to obtain economies of scale. Horizontal M\&A help companies restructure assets and resources, thereby improving the efficiency of management. Technology diffusion from the same industry help companies complement each other in R\&D and improve product quality and efficiency. In addition, horizontal M\&A can eliminate duplicate labor and achieve efficient use of equipment, thereby reducing fixed production costs. Scholars have made fruitful researches on the motives of horizontal M\&A, and tend to agree that companies can profit from horizontal M\&A. There are mixed results of empirical research on the effect of horizontal M\&A, and cases of M\&A failure occur from time to time. Whether horizontal M\&A can achieve the desired results of managers? This paper chooses the horizontal M\&A events between 1995 and 2005 when both sides of M\&A are listed companies in the United States. Event study method is used to compare the volatility of stock prices in the event window of each participant to test the short-term performance of horizontal M\&A. The empirical results of this paper show that the stock market in the United States has responded about a week before the announcement date of horizontal M\&A due to the lack of standardization of information disclosure or inadequate regulatory means. Horizontal M\&A enhance the shareholder wealth of the targets in the short term, while cause loss of shareholder wealth of the bidders on the announcement day of M\&A.
\end{abstract}

\section{Keywords}

Horizontal Mergers and Acquisitions, Merger Performance, Event Study

\section{Introduction}

Horizontal mergers and acquisitions (horizontal M\&A), as widely adopted by 
growth companies and early-stage enterprises, occupy an important position in the global wave of mergers and acquisitions. According to the SDC Platinum database, in the United States, where the wave of mergers and acquisitions was most active, there were 3214 horizontal mergers and acquisitions between 1976 and 2016. As a fast-growing developing country, horizontal mergers and acquisitions have always been the dominant way of mergers and acquisitions in China. According to Wind database, between 2000 and 2017, there were 49,562 mergers and acquisitions in Chinese enterprises, including 20,627 horizontal mergers and acquisitions. The statistical results of mergers and acquisitions showed that horizontal integration accounted for $41.63 \%$ of all M\&A motives.

After the completion of the horizontal M\&A transaction, can the business performance of the company meet the expectations of the manager? The actual M\&A case did not give a consistent answer.

In 1995, Kimberly-Clark acquired the paper giant Scott Paper for the expansion of its business. After the horizontal merger was completed, Kimberly-Clark announced that the first year after the merger achieved nearly \$2.5 million in cost savings, and the next year realized 4 million. The dollar savings, the third year of cost savings is up to 5 million US dollars [1]. Another example is the merger of Hewlett-Packard (HP) and Compaq, the newly merged company halved the original 109 product distribution centers. In the first nine months of the merger, more than $\$ 1$ billion in cost savings related to the supply chain, such as raw material procurement, logistics and factory rationalization, was achieved [2]. In 2016, after DiDi announced the acquisition of Uber China, DiDi accounted for over $90 \%$ of the domestic taxi software market in China. The decline in costs and the increase in sales have brought huge synergies to $\mathrm{DiDi}$. The total number of orders dropped from 1.4 billion in 2015 to more than 7.43 billion at the end of 2017, and the number of users increased from 150 million in 2015 to more than 450 million users by the end of 2017 [3].

Behind the successful horizontal mergers and acquisitions, the case of failed M\&A happens sometimes. Marks\&Mirvis [4] point out that nearly three-quarters of M\&A is unsatisfactory when measuring M\&A performance by stock value, return on investment, and post-merger profitability metrics. Mark L. Sirower, professor of New York University's Stern School of Business and the author of "The Traps of Synergies", analyzes the stocks of 100 large M\&A transactions between 1994 and 1997. The results show that after one year of completion of the merger, the acquirers' stock price average 8.6\% lower than the S\&P 500, and 32 companies have stock prices below the prices 5 days before the M\&A deal. What factors affect the performance of corporate mergers and acquisitions?

Since the actual horizontal merger cases do not give a consistent answer, we empirically investigate whether merging firms realize benefits associated with shareholder wealth using firm-level data from same-industry mergers with announcement dates ranging from 1995 to 2005 in USA. To test whether merged firms realize any benefits with shareholder wealth, we compare the abnormal 
return of stock under three event windows $(-30,+30),(-10,+10)$ and $(-5,+5)$. The abnormal return of stock is defined as the difference between the actual return of stock and the expected return of stock under event windows. We also empirically investigate whether the abnormal return of stocks are different in industries. For this purpose, we also split full sample according to industries into four subsamples.

We find acquirers obtain significant negative abnormal return of stocks on the M\&A announcement date which means that the shareholder's wealth of acquirers suffer loss. On the day of the M\&A announcement, targets obtain significant positive abnormal return of stocks, indicating that the stock market of targets show a very positive response to the release of the horizontal M\&A information. Horizontal M\&A increase the shareholder wealth of the targets in the short term. Similar conclusions can be verified in the empirical results of the subsamples.

We also find the abnormal return of stocks is different in industries. We find horizontal mergers and acquisitions have the most obvious impact on the shareholder wealth of targets in the manufacturing and wholesale and retail industries. Due to insufficient information disclosure or inadequate supervision means, the stock market of targets in the manufacturing and service industries react in advance to the announcement of mergers about 5 days, while the stock market of targets in the wholesale and retail industry react in advance about 2 days, and the stock market of targets in the natural resources industry do not have a reaction in advance. The stock market of acquirers in the natural resources industry shows a negative reaction 1 day ahead of the horizontal merger announcement. The stock market of acquirers in the service industry shows a positive response 1 day in advance too. However, this positive reaction lack continuity, and the stock market reaction turn from positive to negative on the M\&A announcement date. The stock market of acquirers in the manufacturing and wholesale and retail industries do not have a negative reaction in advance.

This study utilizes a novel and large dataset of merging firms. The findings support the conclusions of previous scholars on horizontal mergers and acquisitions enhance the wealth of the targets' shareholders. For the mixed results on how horizontal mergers and acquisitions affect acquirers' shareholders, this study also provide an empirical answer.

Our study differs from previous empirical works on mergers in two respects. First, we use firm-level data taking place in many industries such as manufacturing, wholesale, retail trade and service and natural resources, while previous empirical works ignore industry factors. In fact, the horizontal mergers and acquisitions performance of different industries will be different. Analysis of full samples and subsamples also make our finding more convincing. Second, we use the average abnormal return of stock on announcement date(AAR) and the Cumulative average abnormal return of stock(CAAR) under different event windows to test the hypotheses on horizontal M\&A, while previous empirical 
works only use one of them. Different test indicators help us to analyze the horizontal M\&A performance on the announcement day and the performance within the event window.

When enterprises make horizontal M\&A decisions, it is a topic of great concern to choose which targets can improve their operational efficiency. Our research point out that horizontal mergers and acquisitions do not always bring benefits to the acquirers, and managers should make a rational valuation of the targets. Our findings give managers guidance in making horizontal M\&A decisions.

The rest of this article is organized as follows. Section 2 develops the hypotheses on horizontal M\&A effects relying on theoretical work on synergy theory and signal transmission theory. Section 3 describes the hypothesis testing method and the details of the data sample that we utilize. Section 4 discusses the results of the empirical analyses. Finally, Section 5 concludes the paper by summarizing the findings and limitations of the study and providing guidance for follow-up research.

\section{Literature Review}

Horizontal mergers and acquisitions may increase shareholder value through: 1) achieving synergies [5] [6] [7] [8], 2) Gaining market power [1] [5] [9] [10] [11].

The empirical work on horizontal mergers and acquisitions generally use Event-study method to compare the company's abnormal return of stocks in different event windows. According to the empirical studies, the shareholder wealth of the targets improves after merging. There are different voices about whether horizontal mergers and acquisitions can enhance the shareholder wealth of the acquirers.

Xiaohui $\mathrm{Xu}$ [12] focuses on the M\&A events of Chinese listed companies from the 2003 to 2013 , selecting three event windows $(-1,+1),(-5,5)$ and $(-10,10)$ respectively to study the impact of industry similarity on the short-term performance of the acquirers and targets. The author finds the higher the similarity between the merging firms, the better the effect of horizontal mergers and acquisitions. Duso\&Gugler [13] use stock data of 167 global horizontal mergers and acquisitions events that suffered from EU antitrust review between 1990 and 2002 , the authors select four event windows $(-2,+2),(-5,+5),(-25,+5)$ and $(-50,+5)$ and find that both acquirers and targets obtain positive stock abnormal returns in the four event windows. Wårell [14] investigates two major mining companies Rio Tinto and North Ltd horizontal mergers in 2000, the results show that on the M\&A announcement date, the target North Ltd achieves significant positive abnormal return of $12.33 \%$, and the acquirer Rio Tinto achieves significant positive abnormal return of $1.21 \%$. When the event window is extended to $(-5,+5)$, the results are still similar. Eckbo [15] studies a total of 259 M\&A samples from the same industry in the US mining industry and manufacturing industry. Among them, 76 mergers and acquisitions are questioned by the 
government, claiming that they monopoly the product market. The author select two event windows $(-20,+10)$ and $(-3,+3)$ to examine the response of 76 suspected M\&A events in the stock market. The results show that acquirers realize significant positive abnormal return of $4.85 \%$ and $1.20 \%$ in Window 1 and Window 2, while targets realize abnormal return of $25.03 \%$ and $10.2 \%$ in window 1 and window2.

Different from the results of the above scholars, Shahrur [16] selects three event windows $(-1,0),(-2,+2)$ and $(-10,+10)$. The results show that under the window $(-1,0)$, targets obtain a positive abnormal return of $15.89 \%$, the acquirers receive a negative abnormal return of $-0.61 \%$. This finding shows that targets profit from the horizontal merger, while the short-term merger performance of the acquirers decrease. Whether horizontal mergers and acquisitions bring the short-term improvement of the shareholder wealth still needs further discussion, which provides a breakthrough for the empirical research content of this paper.

From the empirical research of the horizontal M\&A, scholars have different choices in the selection of event windows. Similarly, they usually choose a shorter time span as window 1 such as $(-2,+2),(-3,+3)$ and $(-5,+5)$, choose a longer time span as window 2 such as $(-10,+10),(-20,+10)$ and $(-25,+5)$. Multiple event windows comparison analysis help us to determine when the stock market's response to the announcement.

Similar to the choices of Xiaohui Xu, Duso\&Gugler and Wårell [12] [13] [14], our research use $(-5,+5)$ as window 1 . Similar to the choices of Shahrur and Xiaohui Xu, [12] [16], our research use $(-10,+10)$ as window 2. Different from the above scholars, our research add a longer time span $(-30,+30)$ as window 3 .

For industry differences, Wårell [14] focuses on one deals and Eckbo [15] concentrates on deals in mining and manufacturing industry, we use firm-level data on 583 merger deals taking place in many industries such as manufacturing, wholesale and retail trade, service and natural resources.

\section{Hypotheses}

Synergy theory holds that managers consider maximizing the interests of shareholders when making M\&A decisions. Therefore, during the negotiation process, M\&A transaction can be successfully achieved only when the transaction documents are favorable to the shareholders' wealth of both parties [17]. Therefore, after the horizontal mergers and acquisitions, both parties have strong motivation to integrate resources to obtain economies of scale and thus increase the shareholders' wealth of both side.

The wealth of shareholders mainly comes from the premium income of stock and dividend income. Since dividend income depends on the company's annual profit situation, premium income of stock is an important variable affecting the wealth of shareholders in the short-term view of M\&A [18]. From the perspective of signal transmission theory, horizontal mergers and acquisitions convey to 
the stock market a positive signal that acquirers will expand their scale to achieve economies of scale. This signal gives investors an optimistic expectation of the future development of the acquirers, which will cause the stock price to rise and acquirers obtain a positive stock premium income. The M\&A announcement conveys to the stock investors the signal that the value of the targets is undervalued and the targets will face business restructuring. The companies selected as the M\&A targets have been highly recognized by the acquirers. After obtaining the capital market signal, the investor adjusts the valuation of the targets. Therefore, horizontal mergers can help the targets to obtain positive stock premium income. These theoretical predictions lead to our hypotheses.

Hypothesis 1. Horizontal mergers and acquisitions can increase the shareholder wealth of the acquirers in the short term.

Hypothesis 2. Horizontal mergers and acquisitions can increase the shareholder wealth of the targets in the short term.

\section{Research Method}

In theory, when the capital market is effective, the signals transmitted by horizontal M\&A as a major event will trigger fluctuations in stock prices, which in turn affect the changes in shareholder wealth. This paper uses event-study method to investigate the short-term performance of horizontal mergers and acquisitions.

The spirit of event-study method is to compare the actual stock return rate with the stock return rate under the assumption that the horizontal merger has not occurred which called "the normal stock return rate" of a certain period of observation during the period of the horizontal merger announcement which called "the event windows". Through the analysis of the difference between the actual stock return rate and the normal stock return rate, which called "the abnormal stock return rate", we can conclude whether merging firms improve their shareholder wealth or not.

We use the following steps to carry out our event study.

First, define the event window and the estimation window. The event day refers to the date on which the targets and the acquirers issue horizontal merger announcements in the capital market. The event window is the observation time interval selected to study the impact of horizontal mergers on stock returns. With the extension of the event window, other irrelevant events occurred in the event window, such as the company's announcement of distribution of dividends, also increased the interference with our results. For the consideration of this factors, we select 30 days before and after the event day $(-30,30)$ as the event window 1,10 days before and after the event day $(-10,10)$ as the event window 2 , and 5 days before and after the event day $(-5,5)$ as the event window 3 . We draw our conclusions through comparing the empirical results under different event windows. The estimation window is a certain time range before the event window, and the stock return rate within this time range is the basis for 
calculating the normal stock return rate in the event windows. This paper selects 120 days before the event day and 31 days before the event day $(-120,-31)$ as the estimation window. Figure 1 shows the merger timeline.

Second, calculate the abnormal stock return rate in the event windows. This paper uses market model to estimate the normal stock return rate in the event windows. Market model assumes that there is a stable linear relationship between the actual stock return rate and the market stock return rate. Therefore, the linear relationship expression can be determined by using the actual stock return rate and the market stock return rate in the estimation window. Giving this linear relationship expression, we can calculate the normal stock return rate in the event window using the market stock return rate during that time.

In the estimation window $(-120,31)$, we use the ordinary least squares (OLS) to calculate the estimated coefficients $\hat{\alpha}_{i}, \hat{\beta}_{i}$ and residual $\varepsilon_{i t}$ for each stock. $R_{i t(e s t)}$ is the stock return rate of $i$ stocks on the $t$ day of the estimation window. $R_{m t}$ is the market stock return rate on $t$ day. We use the S\&P 500 Index to calculate the market stock return rate. $A R_{i t}$ is the abnormal return rate of $i$ stock on the $t$ day. $R_{i t(\text { event })}$ is the stock return rate of $i$ stocks on the $t$ day in the event window. The linear expression between the actual stock return rate and the market stock return rate in the estimation window is estimated as follows:

$$
R_{i t(e s t)}=\hat{\alpha}_{i}+\hat{\beta}_{i} R_{m t(e s t)}+\varepsilon_{i t}
$$

$E\left[R_{i t(\text { event })}\right]$ is the normal stock return rate of stock $i$ in the event windows. We use the following linear expression to calculate $E\left[R_{i t(\text { event })}\right]$ :

$$
E\left[R_{\text {it (event })}\right]=\hat{\alpha}_{i}+\hat{\beta}_{i} R_{m t(\text { event })}
$$

Then, we use the following linear expression to calculate $A R_{i t(\text { event })}$ :

$$
A R_{i t \text { (event })}=R_{i t(\text { event })}-E\left[R_{i t(\text { event })}\right]
$$

Third, statistical test the abnormal stock return rate in the event windows. When we estimate the abnormal stock return rate of each stock in the event window, it is necessary to test whether the abnormal stock return rate is significantly different from zero in order to judge whether the occurrence of horizontal mergers and acquisitions has a significant impact on the shareholder wealth.

The abnormal stock return rate $A R_{\text {it (event) }}$ of all $N$ stocks in the event window

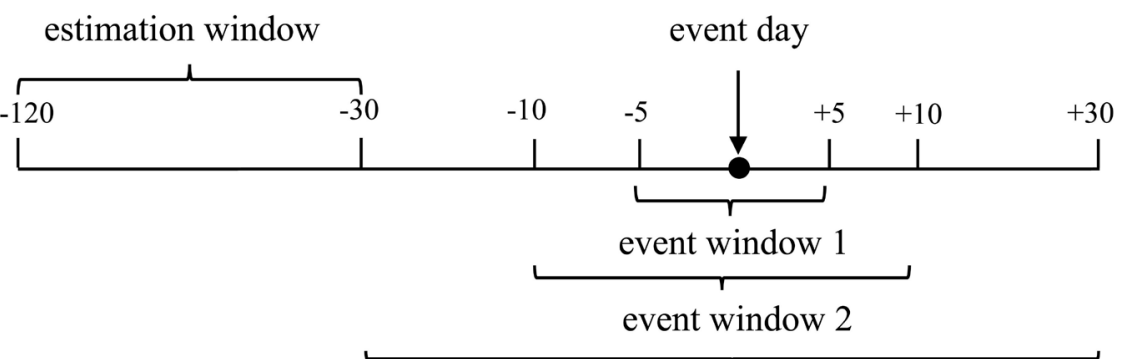

event window 3

Figure 1. Merger timeline. 
constitutes a sample with $N \times L 2$ observations. $L 2$ is the number of days in the event windows. Each abnormal stock return rate $A R_{i t(\text { event })}$ is a random variable. To test whether the abnormal stock return rate is significantly different from zero, it is necessary to aggregate the construction statistics for these observations. We construct the following two statistics for analysis.

$$
\begin{aligned}
& A A R_{t(\text { event })}=\frac{1}{N} \sum_{i=1}^{N} A R_{i t(\text { event })} \\
& \operatorname{CAAR}_{\left(t_{1}, t_{2}\right)}=\frac{1}{N} \sum_{i=1}^{N} C A R_{i\left(t_{1}, t_{2}\right)}
\end{aligned}
$$

This paper uses independent sample $T$ test to determine whether $A A R_{t(\text { event })}$ and $C A A R_{\left(t_{1}, t_{2}\right)}$ are significantly different from zero in event windows. The $T$ statistics are as follows.

$$
\begin{aligned}
t_{A A R} & =\frac{A A R_{t}}{S_{A R_{i t(\text { event })}} / \sqrt{N}} \\
t_{C A A R} & =\frac{C A A R_{\left(t_{1}, t_{2}\right)}}{S_{C A R_{i\left(t_{1}, t_{2}\right)}} / \sqrt{N}}
\end{aligned}
$$

\section{Sampling Frame}

The precondition for the application of the event-study method is that the stock market is efficient. The US stock market started very early, and scholars have carried out a large number of empirical studies on whether the US stock market is efficient. The research results tend to be consistent and the US stock market is effective.

Wurgler [19] analyzes the US stock market by collecting data from the Dow Jones Industrial Average from 1897 to 1959 and the S\&P 500 index from 1929 to 1959. The results show that the US stock market has reached a weak effective level in the middle of the 20th century, and the price of the stock already contains all the historical information. Fama [20] uses the random walk model to investigate 30 stocks in the Dow Jones Industrial Index from 1957 to 1968. The results show that transaction costs have an impact on the efficiency of the stock market. Under the consideration of transaction costs, the US stock market is a weak and effective market. Box\&Pierce [21] uses the autoregressive conditional heteroskedasticity model $(\mathrm{ARCH})$ to test the efficiency of the US stock market. The $\mathrm{T}$ test results show that the stock historical price of the New York stock market cannot predict future stock return, so the stock market is efficient. For more literature on the efficiency of the US securities market, see the literature review by scholars [20] [22] [23].

We compile the sample of horizontal merger deals using Security Database Corporation's (SDC) U.S. Mergers and Acquisition database. The daily stock return data of US listed companies used in this study are from the Center for Research of Security Prices database (CRSP). Our aim is to investigate whether 
merging firms improve their shareholder wealth.

We impose the following filters to identify a sample of deals where synergy would be most likely enacted. First, to restructure asset, deals should be completed and the acquirers should purchase control rights in the targets. Therefore, after the transaction is completed, the shareholding of the acquirers by the acquirer must exceed 50\%. Second, acquirers and targets should operate in the same industry. For this purpose, mergers are restricted to the ones where acquirers and targets share the same 2-digit Industry Sector (IS) code. Third, we drop all merger deals by the same target or acquirers (except for the first one) in order to attribute the change in shareholder wealth to the specific event. Fourth, acquirers and targets must have 61 days of stock return data in the event window $(-30,+30)$. Fifth, acquirers and targets must have 90 days of stock return data in the estimation window $(-120,-31)$. These filters produce 583 deals with announcement dates ranging from January 1995 to November 2005. Table 1 tabulates the distribution of the deals according to industry. $53.52 \%$ percent of deals take place in the manufacturing industry, $6.17 \%$ percent in natural resources and $34.82 \%$ percent in service industry and $5.49 \%$ percent in wholesale and retail industry.

\section{Results}

In order to present the empirical results more comprehensively, this study first analyzes the whole sample, and then splits the sample into four sub-samples of manufacturing, service, natural resources, and wholesale and retail. On the one hand, the sub-sample study further validates the conclusions of the whole sample. On the other hand, the sub-sample study can explore the differences in inter-industry results and the particularities of each industry.

The first hypothesis investigates whether the shareholder wealth of the acquirers improves. If the hypothesis holds, the average abnormal return of stocks (AAR) on announcement date and the cumulative average abnormal return of stocks (CAAR) in the event windows should prove significantly greater than zero.

Figure 2 and Figure 3 show the full sample daily average abnormal return of stocks (AAR) of the acquirers and the targets. On the day of the M\&A announcement, the average abnormal return of stocks on both the acquirer and the acquirer peaked, and were numerically significantly different from any other day

Table 1. Industry distribution of sample deals.

\begin{tabular}{ccc}
\hline 2-Digit IS code & Industry definition & Sample total (\%) \\
\hline AA-AV & Manufacturing & $53.52 \%$ \\
EA-EC & Natural resources & $6.17 \%$ \\
BA-BS & Service & $34.82 \%$ \\
CA-CG & wholesale and retail & $5.49 \%$ \\
Sample size $(\mathrm{N})$ & & \\
\hline
\end{tabular}




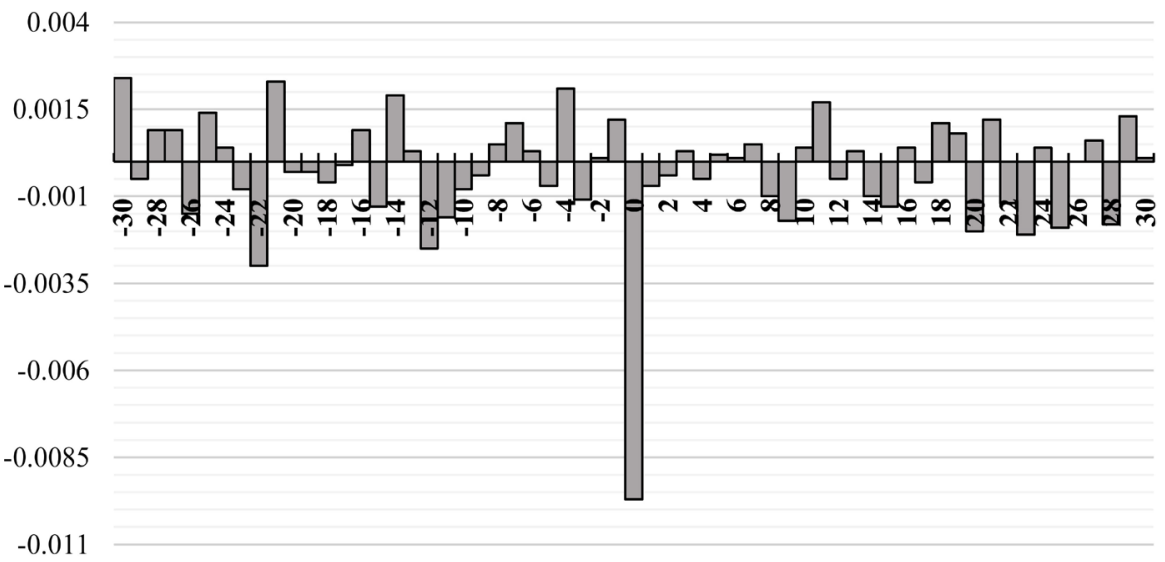

Figure 2. Full sample AAR of the acquirers.

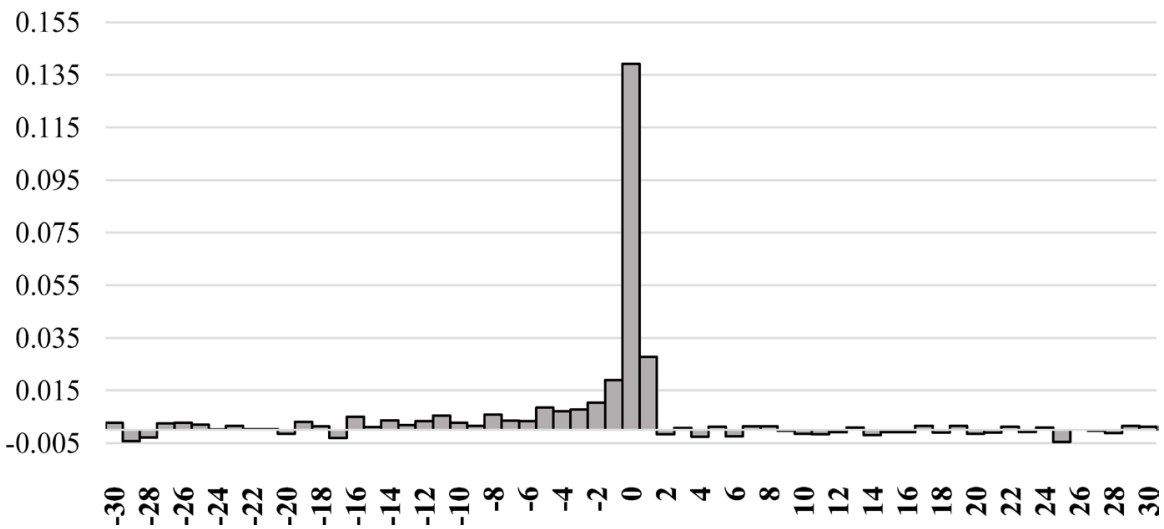

Figure 3. Full sample AAR of the targets.

in the event window. The AAR of the acquirers before the announcement date shows the fluctuation characteristics of positive and negative random walks, and the fluctuation range is between $-0.30 \%$ and $0.24 \%$. On the announcement date, the AAR of the acquirers plummeted to $-0.97 \%$ suddenly. This shows that the stock market give a negative reaction to the acquirers on the M\&A announcement day. We found that between $\mathrm{T}=-30$ and $\mathrm{T}=-17$, the AAR of the targets show positive and negative random walk distribution characteristics too. Different from the acquirers, between $\mathrm{T}=-16$ and $\mathrm{T}=0$, the AAR of the targets is increasing day by day. This phenomenon indicates that the news of the horizontal mergers and acquisitions by the acquirer has been informed in advance by the stock market, and the stock price has already responded before the announcement date. On the announcement date, the AAR of the targets rise to $13.91 \%$ suddenly. This shows that the stock market give a positive reaction to the targets on the M\&A announcement day.

In order to verify the above findings, we further conduct full sample statistical $\mathrm{T}$ test on the AAR and CAAR of the acquirers and the targets. Table 2 and Table 3 show the full sample AAR and CAAR T test results. From Table 2, We found the stock return of the acquirers decreased by $0.97 \%$ and pass the statistical significance test (under the condition of $1 \%$ of the significance level) on the $\mathrm{M}$ 
Table 2. T test on full sample AAR of the acquirers and the targets

\begin{tabular}{|c|c|c|c|c|c|c|}
\hline \multirow{2}{*}{$\mathrm{t}$} & \multicolumn{3}{|c|}{ acquirers } & \multicolumn{3}{|c|}{ targets } \\
\hline & mean & t-statistics & p-statistics & mean & t-statistics & p-statistics \\
\hline-30 & 0.0024 & $(1.2863)$ & $(0.1988)$ & 0.0028 & $(1.5866)$ & $(0.1130)$ \\
\hline-29 & -0.0005 & $(-0.3062)$ & $(0.7596)$ & $-0.0043^{* *}$ & $(-2.5285)$ & $(0.0117)$ \\
\hline-28 & 0.0009 & $(0.4784)$ & $(0.6325)$ & -0.0028 & $(-1.4544)$ & $(0.1463)$ \\
\hline-27 & 0.0009 & $(0.4371)$ & $(0.6622)$ & 0.0025 & $(1.3650)$ & $(0.1727)$ \\
\hline-26 & -0.0015 & $(-1.0823)$ & $(0.2796)$ & 0.0028 & $(1.3264)$ & $(0.1851)$ \\
\hline-25 & 0.0014 & $(0.6133)$ & $(0.5399)$ & 0.0020 & $(1.0717)$ & $(0.2842)$ \\
\hline-24 & 0.0004 & $(0.2196)$ & $(0.8263)$ & 0.0001 & $(0.0389)$ & $(0.9690)$ \\
\hline-23 & -0.0008 & $(-0.4702)$ & $(0.6384)$ & 0.0015 & $(0.8030)$ & $(0.4222)$ \\
\hline-22 & $-0.0030^{*}$ & $(-1.8709)$ & $(0.0619)$ & 0.0003 & $(0.1833)$ & $(0.8546)$ \\
\hline-21 & 0.0023 & (1.4037) & $(0.1609)$ & 0.0003 & $(0.1982)$ & $(0.8430)$ \\
\hline-20 & -0.0003 & $(-0.1726)$ & $(0.8630)$ & -0.0015 & $(-0.7648)$ & $(0.4446)$ \\
\hline-19 & -0.0003 & $(-0.1680)$ & $(0.8666)$ & 0.0030 & $(1.4654)$ & $(0.1432)$ \\
\hline-18 & -0.0006 & $(-0.3679)$ & $(0.7131)$ & 0.0014 & $(0.7349)$ & $(0.4626)$ \\
\hline-17 & -0.0001 & $(-0.0481)$ & $(0.9617)$ & $-0.0030^{*}$ & $(-1.6849)$ & $(0.0924)$ \\
\hline-16 & 0.0009 & $(0.4923)$ & $(0.6227)$ & $0.0050^{* * *}$ & $(2.8605)$ & $(0.0044)$ \\
\hline-15 & -0.0013 & $(-0.8352)$ & $(0.4039)$ & 0.0011 & $(0.6177)$ & $(0.5369)$ \\
\hline-14 & 0.0019 & $(1.0652)$ & $(0.2872)$ & 0.0037 & $(1.4277)$ & $(0.1538)$ \\
\hline-13 & 0.0003 & $(0.1783)$ & $(0.8586)$ & 0.0018 & $(0.8657)$ & $(0.3869)$ \\
\hline-12 & -0.0025 & $(-1.4720)$ & $(0.1416)$ & $0.0034^{* *}$ & $(2.0657)$ & $(0.0392)$ \\
\hline-11 & -0.0016 & $(-0.9706)$ & $(0.3322)$ & $0.0055^{\star *}$ & $(2.5617)$ & $(0.0106)$ \\
\hline-10 & -0.0008 & $(-0.5350)$ & $(0.5928)$ & 0.0028 & $(1.4586)$ & $(0.1451)$ \\
\hline-9 & -0.0004 & $(-0.2579)$ & $(0.7966)$ & 0.0016 & $(0.8136)$ & $(0.4161)$ \\
\hline-8 & 0.0005 & $(0.3135)$ & $(0.7540)$ & $0.0058^{* * *}$ & $(3.0244)$ & $(0.0026)$ \\
\hline-7 & 0.0011 & $(0.5728)$ & $(0.5670)$ & $0.0035^{* *}$ & $(1.9971)$ & $(0.0462)$ \\
\hline-6 & 0.0003 & $(0.1411)$ & $(0.8878)$ & $0.0033^{*}$ & $(1.7394)$ & $(0.0824)$ \\
\hline-5 & -0.0007 & $(-0.4915)$ & $(0.6232)$ & $0.0085^{\star * *}$ & $(4.2072)$ & $(0.0000)$ \\
\hline-4 & 0.0021 & $(1.0513)$ & $(0.2936)$ & $0.0072^{* * *}$ & $(3.9853)$ & $(0.0001)$ \\
\hline-3 & -0.0011 & $(-0.5590)$ & $(0.5764)$ & $0.0078^{* * *}$ & $(3.8933)$ & $(0.0001)$ \\
\hline-2 & 0.0001 & $(0.0338)$ & $(0.9731)$ & $0.0104^{* * *}$ & $(4.9772)$ & $(0.0000)$ \\
\hline-1 & 0.0012 & $(0.7695)$ & $(0.4419)$ & $0.0190^{* * *}$ & $(7.5616)$ & $(0.0000)$ \\
\hline 0 & $-0.0097^{* * *}$ & $(-3.9065)$ & $(0.0001)$ & $0.1391^{* * *}$ & $(17.2129)$ & $(0.0000)$ \\
\hline 1 & -0.0007 & $(-0.3923)$ & $(0.6950)$ & $0.0278^{* * *}$ & $(5.7712)$ & $(0.0000)$ \\
\hline 2 & -0.0004 & $(-0.1920)$ & $(0.8478)$ & -0.0016 & $(-1.1764)$ & $(0.2398)$ \\
\hline 3 & 0.0003 & $(0.1986)$ & $(0.8426)$ & 0.0008 & $(0.5355)$ & $(0.5925)$ \\
\hline 4 & -0.0005 & $(-0.2958)$ & $(0.7675)$ & $-0.0026^{* *}$ & $(-2.1146)$ & $(0.0348)$ \\
\hline
\end{tabular}




\section{Continued}

\begin{tabular}{|c|c|c|c|c|c|c|}
\hline 5 & 0.0002 & $(0.1160)$ & $(0.9077)$ & 0.0013 & $(0.5183)$ & $(0.6044)$ \\
\hline 6 & 0.0001 & $(0.0318)$ & $(0.9746)$ & $-0.0024^{* *}$ & $(-1.9659)$ & $(0.0497)$ \\
\hline 7 & 0.0005 & $(0.2516)$ & $(0.8014)$ & 0.0014 & $(1.0153)$ & $(0.3103)$ \\
\hline 8 & -0.0010 & $(-0.4939)$ & $(0.6216)$ & 0.0014 & $(1.0517)$ & $(0.2933)$ \\
\hline 9 & -0.0017 & $(-0.8758)$ & $(0.3815)$ & -0.0003 & $(-0.2393)$ & $(0.8110)$ \\
\hline 10 & 0.0004 & $(0.2228)$ & $(0.8238)$ & -0.0015 & $(-1.1632)$ & $(0.2451)$ \\
\hline 11 & 0.0017 & $(0.9506)$ & $(0.3422)$ & -0.0017 & $(-1.5698)$ & $(0.1169)$ \\
\hline 12 & -0.0005 & $(-0.2273)$ & $(0.8202)$ & -0.0009 & $(-0.7166)$ & $(0.4738)$ \\
\hline 13 & 0.0003 & $(0.1810)$ & $(0.8564)$ & 0.0010 & $(0.8665)$ & $(0.3865)$ \\
\hline 14 & -0.0010 & $(-0.6165)$ & $(0.5378)$ & -0.0020 & $(-1.5697)$ & $(0.1169)$ \\
\hline 15 & -0.0013 & $(-0.7239)$ & $(0.4694)$ & -0.0009 & $(-0.6028)$ & $(0.5468)$ \\
\hline 16 & 0.0004 & $(0.2639)$ & $(0.7920)$ & -0.0009 & $(-0.6981)$ & $(0.4853)$ \\
\hline 17 & -0.0006 & $(-0.3469)$ & $(0.7288)$ & 0.0016 & $(0.7963)$ & $(0.4261)$ \\
\hline 18 & 0.0011 & $(0.7178)$ & $(0.4732)$ & -0.0011 & $(-0.9783)$ & $(0.3283)$ \\
\hline 19 & 0.0008 & $(0.4945)$ & $(0.6211)$ & 0.0016 & (1.1218) & $(0.2623)$ \\
\hline 20 & -0.0020 & $(-1.2666)$ & $(0.2058)$ & -0.0015 & $(-1.1064)$ & $(0.2689)$ \\
\hline 21 & 0.0012 & $(0.7282)$ & $(0.4668)$ & -0.0010 & $(-0.8293)$ & $(0.4072)$ \\
\hline 22 & -0.0012 & $(-0.7371)$ & $(0.4614)$ & 0.0012 & $(0.9193)$ & $(0.3582)$ \\
\hline 23 & -0.0021 & $(-1.1890)$ & $(0.2349)$ & -0.0007 & $(-0.5624)$ & $(0.5740)$ \\
\hline 24 & 0.0004 & $(0.2395)$ & $(0.8108)$ & 0.0010 & $(0.8533)$ & $(0.3938)$ \\
\hline 25 & -0.0019 & $(-1.2223)$ & $(0.2221)$ & $-0.0045^{* * *}$ & $(-3.4451)$ & $(0.0006)$ \\
\hline 26 & -0.0000 & $(-0.0177)$ & $(0.9859)$ & 0.0000 & $(0.0079)$ & $(0.9937)$ \\
\hline 27 & 0.0006 & $(0.3553)$ & $(0.7225)$ & -0.0003 & $(-0.2035)$ & $(0.8388)$ \\
\hline 28 & -0.0018 & $(-1.1933)$ & $(0.2333)$ & -0.0012 & $(-0.9307)$ & $(0.3523)$ \\
\hline 29 & 0.0013 & $(0.7665)$ & $(0.4437)$ & 0.0015 & $(1.3125)$ & $(0.1898)$ \\
\hline 30 & 0.0001 & $(0.0687)$ & $(0.9453)$ & 0.0012 & $(0.9054)$ & $(0.3655)$ \\
\hline
\end{tabular}

Notes: ${ }^{\star}$ Denotes statistical significance at $10 \%$ levels; ${ }^{* *}$ Denotes statistical significance at $5 \%$ levels; ${ }^{* *}$ Denotes statistical significance at $1 \%$ levels.

Table 3. $\mathrm{T}$ test on full sample CAAR of the acquirers and the targets.

\begin{tabular}{|c|c|c|c|c|c|c|}
\hline \multirow{2}{*}{ windows } & \multicolumn{3}{|c|}{ acquirers } & \multicolumn{3}{|c|}{ targets } \\
\hline & $(-30,+30)$ & $(-10,+10)$ & $(-5,+5)$ & $(-30,+30)$ & $(-10,+10)$ & $(-5,+5)$ \\
\hline mean & -0.0159 & -0.0104 & -0.0092 & $0.2514^{* * *}$ & $0.2333^{* * *}$ & $0.2177^{* * *}$ \\
\hline t-statistics & $(-0.8740)$ & $(-1.0910)$ & $(-1.3666)$ & $(16.4000)$ & (22.1433) & (22.9245) \\
\hline p-statistics & $(0.3825)$ & $(0.2757)$ & $(0.1723)$ & $(0.0000)$ & $(0.0000)$ & $(0.0000)$ \\
\hline $\mathrm{N}$ & 583 & 583 & 583 & 583 & 583 & 583 \\
\hline
\end{tabular}

Notes: ${ }^{\star}$ Denotes statistical significance at $10 \%$ levels; ${ }^{* *}$ Denotes statistical significance at $5 \%$ levels; ${ }^{* * *}$ Denotes statistical significance at $1 \%$ levels. 
\& A announcement day. This finding verify that the shareholder's wealth of the acquirers suffer a loss on the M\&A announcement day. We find the stock return rate of the acquirers decreased by $0.30 \%$ on $\mathrm{T}=-22$, and pass the statistical significance test (under the condition of $10 \%$ of the significance level). On other observation days, the stock return rate of the acquirers don't pass the significance test. Considering that the $\mathrm{T}=-22$ day is far from the announcement day, the phenomenon that the stock return rate declines may come from the interference of other information in the stock market. Through the full sample AAR T test of the acquirers in the event window, it is assumed that Hypothesis 1 is not supported. On the contrary, the release of the horizontal M\&A information reduces the shareholder's wealth of the acquirers on the announcement day, and the stock return rate decreases by $0.97 \%$.

From Table 2, we find the targets obtain statistical significant stock abnormal returns between $\mathrm{T}=-8$ and $\mathrm{T}=+1$. It is worth noting that between $\mathrm{T}=-5$ and $\mathrm{T}=+1$, the targets obtain $0.85 \%, 0.72 \%, 0.78 \%, 1.04 \%, 1.90 \%, 13.91 \%$, and $2.78 \%$ of the stock abnormal returns respectively, which all pass the statistical significance test (under the condition of $1 \%$ of the significance level). This shows that the impact of the M\&A announcement on the stock price is especially concentrated from 5 days before the announcement date to 1 day after the announcement date. The stock market has already responded one week before the announcement day. Our findings support hypothesis 2 .

From Table 3, we find the acquirers lost a total of $1.59 \%, 1.04 \%$ and $0.92 \%$ of the stock returns in $(-30,+30),(-10,+10)$ and $(-5,+5)$. However, the CAAR of the acquirers in three event windows are not statistically different from zero. We also find the targets obtain a total of $25.14 \%, 23.33 \%$ and $21.77 \%$ of the stock returns in $(-30,+30),(-10,+10)$ and $(-5,+5)$. Different from the acquirers, the CAAR of the targets in three event windows are statistically different from zero (under the condition of $1 \%$ of the significance level). Our findings are further contrary to hypothesis 1 .

Table 4 and Table 5 show the AAR and CAAR of the acquirers in different industries. From Table 4, we find the AAR of the acquirers in manufacturing industry fell by an average of $0.94 \%$, the AAR of the acquirers in service industry fell by an average of $0.96 \%$, and is significantly different from zero (under the condition of $5 \%$ of the significance level) on the announcement day. Different from manufacturing industry, the AAR of the acquirers in service industry increase by an average of $0.57 \%$ on the day before the announcement day, and is significantly different from zero (under the condition of $5 \%$ of the significance level). This indicates that the service stock market has responded positively to the horizontal merger and acquisition news one day ahead of schedule. However, this positive response of the service industry stock market lack continuity and turn from positive to negative on the announcement day. On $\mathrm{T}=-1$, the AAR of the acquirers in natural resource industry decrease by an average of $1.01 \%$, and is significantly different from zero (under the condition of $10 \%$ of the significance 
Table 4. T test on subsample AAR of the acquirers in different industries.

\begin{tabular}{|c|c|c|c|c|c|c|c|c|c|c|c|c|}
\hline \multirow{2}{*}{$\mathrm{t}$} & \multicolumn{3}{|c|}{ manufacturing } & \multicolumn{3}{|c|}{ service } & \multicolumn{3}{|c|}{ wholesale and retail } & \multicolumn{3}{|c|}{ natural resources } \\
\hline & mean & t-statistics & p-statistics & mean & $\mathrm{t}$-statistics & p-statistics & mean & t-statistics & p-statistics & mean & t-statistics & p-statistics \\
\hline-30 & 0.0025 & $(1.2156)$ & $(0.2250)$ & 0.0014 & $(0.3728)$ & $(0.7097)$ & 0.0063 & $(0.5711)$ & $(0.5721)$ & 0.0035 & $(0.4690)$ & $(0.6420)$ \\
\hline-29 & -0.0003 & $(-0.1543)$ & $(0.8775)$ & -0.0010 & $(-0.3090)$ & $(0.7577)$ & -0.0046 & $(-0.4901)$ & $(0.6275)$ & 0.0040 & $(0.6300)$ & $(0.5328)$ \\
\hline-28 & 0.0013 & $(0.5417)$ & $(0.5884)$ & 0.0023 & $(0.5842)$ & $(0.5598)$ & -0.0063 & $(-0.9163)$ & $(0.3666)$ & -0.0034 & $(-0.5891)$ & $(0.5596)$ \\
\hline-27 & 0.0009 & $(0.2933)$ & $(0.7695)$ & -0.0009 & $(-0.3192)$ & $(0.7499)$ & 0.0037 & $(0.3956)$ & $(0.6951)$ & 0.0088 & $(1.3681)$ & $(0.1800)$ \\
\hline-26 & -0.0018 & $(-0.8736)$ & $(0.3830)$ & 0.0017 & $(0.7691)$ & $(0.4427)$ & $-0.0112^{* *}$ & $(-2.3547)$ & $(0.0250)$ & $-0.0084^{\star *}$ & $(-2.2644)$ & $(0.0298)$ \\
\hline-25 & 0.0045 & $(1.4429)$ & $(0.1501)$ & -0.0020 & $(-0.4842)$ & $(0.6288)$ & -0.0005 & $(-0.1052)$ & $(0.9169)$ & -0.0047 & $(-0.7405)$ & $(0.4640)$ \\
\hline-24 & 0.0008 & $(0.3160)$ & $(0.7522)$ & -0.0019 & $(-0.7527)$ & $(0.4525)$ & -0.0057 & $(-0.8787)$ & $(0.3864)$ & $0.0151^{* *}$ & $(2.2822)$ & $(0.0287)$ \\
\hline-23 & -0.0013 & $(-0.5992)$ & $(0.5495)$ & -0.0006 & $(-0.1925)$ & $(0.8475)$ & 0.0056 & $(0.8893)$ & $(0.3807)$ & -0.0033 & $(-0.4842)$ & $(0.6312)$ \\
\hline-22 & $-0.0051^{* *}$ & $(-2.1857)$ & $(0.0296)$ & -0.0007 & $(-0.2471)$ & $(0.8051)$ & -0.0011 & $(-0.1902)$ & $(0.8504)$ & -0.0002 & $(-0.0316)$ & $(0.9750)$ \\
\hline-21 & 0.0007 & $(0.3003)$ & $(0.7641)$ & $0.0067^{\star *}$ & $(2.3692)$ & $(0.0188)$ & -0.0034 & $(-0.6013)$ & $(0.5520)$ & -0.0034 & $(-0.7496)$ & $(0.4585)$ \\
\hline-20 & -0.0009 & $(-0.3782)$ & $(0.7055)$ & 0.0012 & $(0.4024)$ & $(0.6878)$ & -0.0085 & $(-1.2399)$ & $(0.2243)$ & 0.0033 & $(0.5191)$ & $(0.6070)$ \\
\hline-19 & 0.0042 & $(1.6266)$ & $(0.1048)$ & -0.0053 & $(-1.3181)$ & $(0.1890)$ & -0.0084 & $(-1.0141)$ & $(0.3184)$ & -0.0047 & $(-0.9604)$ & $(0.3435)$ \\
\hline-18 & 0.0018 & $(0.7662)$ & $(0.4442)$ & -0.0022 & $(-0.7041)$ & $(0.4822)$ & -0.0055 & $(-1.1575)$ & $(0.2559)$ & -0.0084 & $(-1.4640)$ & $(0.1521)$ \\
\hline-17 & -0.0001 & $(-0.0520)$ & $(0.9586)$ & 0.0010 & $(0.2810)$ & $(0.7790)$ & -0.0024 & $(-0.4880)$ & $(0.6290)$ & -0.0037 & $(-0.9182)$ & $(0.3648)$ \\
\hline-16 & -0.0031 & $(-1.2494)$ & $(0.2124)$ & $0.0053^{*}$ & $(1.7349)$ & $(0.0843)$ & -0.0013 & $(-0.2327)$ & $(0.8175)$ & $0.0125^{\star *}$ & $(2.3072)$ & $(0.0271)$ \\
\hline-15 & 0.0002 & $(0.0774)$ & $(0.9384)$ & -0.0008 & $(-0.3111)$ & $(0.7560)$ & -0.0081 & $(-1.5668)$ & $(0.1273)$ & -0.0101 & $(-1.5045)$ & $(0.1414)$ \\
\hline-14 & 0.0039 & $(1.4469)$ & $(0.1489)$ & 0.0006 & $(0.1994)$ & $(0.8421)$ & -0.0043 & $(-0.9076)$ & $(0.3711)$ & -0.0019 & $(-0.3739)$ & $(0.7107)$ \\
\hline-13 & 0.0005 & $(0.2115)$ & $(0.8326)$ & -0.0011 & $(-0.4877)$ & $(0.6263)$ & -0.0070 & $(-1.3172)$ & $(0.1974)$ & $0.0126^{* *}$ & $(2.6651)$ & $(0.0116)$ \\
\hline-12 & $-0.0044^{\star}$ & $(-1.7886)$ & $(0.0746)$ & 0.0001 & $(0.0401)$ & $(0.9680)$ & -0.0064 & $(-1.2633)$ & $(0.2159)$ & 0.0024 & $(0.4515)$ & $(0.6544)$ \\
\hline-11 & -0.0006 & $(-0.2413)$ & $(0.8095)$ & -0.0027 & $(-1.0655)$ & $(0.2879)$ & -0.0079 & $(-1.3$ & $(0.1873)$ & 0.0013 & $(0.2575)$ & $(0.7983)$ \\
\hline-10 & -0.0010 & $(-0.4250)$ & $(0.6711)$ & 0.0002 & $(0.0669)$ & $(0.9467)$ & -0.0104 & $(-1.6377)$ & $(0.1116)$ & 0.0037 & $(1.0010)$ & $(0.3237)$ \\
\hline-9 & 0.0005 & $(0.1803)$ & $(0.8570)$ & -0.0010 & $(-0.4719)$ & $(0.6375)$ & -0.0018 & $(-0.2761)$ & $(0.7843)$ & -0.0043 & $(-0.8547)$ & $(0.3985)$ \\
\hline-8 & -0.0005 & $(-0.2295)$ & $(0.8186)$ & 0.0018 & $(0.5670)$ & $(0.5714)$ & -0.0010 & $(-0.1950)$ & $(0.8467)$ & 0.0031 & $(0.5229)$ & $(0.6043)$ \\
\hline-7 & -0.0022 & $(-1.0080)$ & $(0.3142)$ & 0.0058 & (1.3837) & $(0.1680)$ & $0.0102^{*}$ & (1.8926) & $(0.0678)$ & -0.0054 & $(-1.0964)$ & $(0.2804)$ \\
\hline-6 & 0.0027 & $(1.0183)$ & $(0.3093)$ & -0.0021 & $(-0.7822)$ & $(0.4350)$ & -0.0105 & $(-1.5032)$ & $(0.1429)$ & 0.0017 & $(0.2932)$ & $(0.7711)$ \\
\hline-5 & -0.0007 & $(-0.3256)$ & $(0.7450)$ & -0.0013 & $(-0.5186)$ & $(0.6046)$ & -0.0029 & $(-0.5740)$ & $(0.5701)$ & 0.0040 & $(0.7850)$ & $(0.4377)$ \\
\hline-4 & 0.0037 & $(1.3630)$ & $(0.1739)$ & -0.0028 & $(-0.8387)$ & $(0.4026)$ & 0.0140 & (1.2209) & $(0.2313)$ & 0.0054 & $(0.7903)$ & $(0.4347)$ \\
\hline-3 & -0.0009 & $(-0.3611)$ & $(0.7183)$ & -0.0031 & $(-0.7791)$ & $(0.4368)$ & 0.0016 & $(0.2518)$ & $(0.8028)$ & 0.0052 & $(0.5243)$ & $(0.6034)$ \\
\hline-2 & 0.0030 & $(1.0392)$ & $(0.2995)$ & -0.0029 & $(-1.2103)$ & $(0.2276)$ & -0.0022 & $(-0.3391)$ & $(0.7369)$ & -0.0065 & $(-0.6947)$ & $(0.4918)$ \\
\hline-1 & -0.0006 & $(-0.3298)$ & (0.7418) & $0.0057^{\star *}$ & (1.9749) & $(0.0496)$ & 0.0027 & $(0.4548)$ & $(0.6524)$ & $-0.0101^{*}$ & $(-1.8004)$ & $(0.0804)$ \\
\hline 0 & $-0.0094^{\star *}$ & $(-2.5470)$ & $(0.0113)$ & $-0.0096^{* *}$ & $(-2.4738)$ & $(0.0142)$ & -0.0104 & $(-1.3098)$ & $(0.1999)$ & -0.0118 & $(-1.4695)$ & $(0.1506)$ \\
\hline 1 & -0.0040 & $(-1.5550)$ & $(0.1210)$ & 0.0039 & $(1.6472)$ & $(0.1011)$ & 0.0076 & $(1.3867)$ & $(0.1754)$ & -0.0053 & $(-0.8818)$ & $(0.3839)$ \\
\hline 2 & -0.0015 & $(-0.5914)$ & $(0.5547)$ & -0.0002 & $(-0.0590)$ & $(0.9530)$ & -0.0062 & $(-0.6666)$ & $(0.5099)$ & 0.0133 & $(1.6651)$ & $(0.1048)$ \\
\hline 3 & 0.0004 & $(0.1421)$ & $(0.8871)$ & -0.0003 & $(-0.1004)$ & $(0.9202)$ & 0.0058 & $(1.3776)$ & $(0.1782)$ & -0.0015 & $(-0.3809)$ & $(0.7056)$ \\
\hline 4 & -0.0025 & $(-1.0073)$ & $(0.3146)$ & 0.0018 & $(0.5690)$ & $(0.5700)$ & 0.0015 & $(0.2533)$ & $(0.8017)$ & 0.0021 & $(0.4722)$ & $(0.6397)$ \\
\hline
\end{tabular}




\section{Continued}

\begin{tabular}{|c|c|c|c|c|c|c|c|c|c|c|c|c|}
\hline 5 & 0.0005 & $(0.1974)$ & $(0.8436)$ & 0.0005 & $(0.2387)$ & $(0.8116)$ & -0.0060 & $(-0.6526)$ & $(0.5188)$ & 0.0013 & $(0.2466)$ & $(0.8067)$ \\
\hline 6 & .0020 & $(-0.9004)$ & $(0.3686)$ & 0.0041 & $(1.3123)$ & $(0.1909)$ & .0030 & $-0.4099)$ & $(0.6847)$ & -0.0024 & $(-0.5273)$ & $(0.6013)$ \\
\hline 7 & 0.0014 & $(0.6312)$ & $(0.5284)$ & -0.0034 & $(-0.9755)$ & $(0.3305)$ & 0.0015 & $(0.2089)$ & $(0.8359)$ & 0.0132 & (1.6202) & $(0.1142)$ \\
\hline 8 & 0.0008 & $(0.2590)$ & $(0.7958)$ & -0.0032 & $(-1.1505)$ & $(0.2513)$ & 0.0060 & $(1.0551)$ & $(0.2995)$ & $-0.0093^{*}$ & $(-1.8980)$ & $0.0660)$ \\
\hline 9 & -0.0010 & $(-0.3305)$ & $(0.7412)$ & -0.0041 & $(-1.5779)$ & $(0.1162)$ & 0.0086 & $(0.8778)$ & $(0.3868)$ & -0.0045 & $(-0.4783)$ & $(0.6354)$ \\
\hline 10 & -0.0004 & $(-0.1676)$ & $(0.8670)$ & 0.0023 & $(0.7418)$ & $(0.4591)$ & -0.0082 & $(-1.5310)$ & $(0.1359)$ & 0.0044 & $(0.3689)$ & $(0.7145)$ \\
\hline 11 & 0.0011 & $(0.4135)$ & $(0.6795)$ & 0.0016 & $(0.5937)$ & $(0.5534)$ & 0.0093 & (1.4193) & $(0.1658)$ & 0.0008 & $(0.1450)$ & $(0.8856)$ \\
\hline 12 & -0.0024 & $(-0.8764)$ & $(0.3815)$ & 0.0015 & $(0.3916)$ & $(0.69$ & 0.0068 & $(0.8547)$ & $(0.3993)$ & -0 . & $(-0.1997)$ & 0.8429) \\
\hline 13 & -0.0035 & $(-1.5660)$ & $(0.1184)$ & 0.0044 & $(1.4586)$ & $(0.1462)$ & 0.0107 & (1.5212) & $(0.1383)$ & 0.0010 & $(0.2147)$ & $(0.8313)$ \\
\hline 14 & -0.0024 & $(-1.0448)$ & $(0.2969)$ & 0.0009 & $(0.2951)$ & $(0.7682)$ & -0.0020 & $(-0.3914)$ & $(0.6982)$ & 0.0010 & $(0.2377)$ & $(0.8135)$ \\
\hline 15 & -0.0031 & $(-1.2885)$ & $(0.1985)$ & 0.0009 & $(0.2702)$ & $(0.7873)$ & 0.0087 & (1.3082) & $(0.2004)$ & -0.0064 & $(-1.2842)$ & $(0.2075)$ \\
\hline 16 & -0.0016 & $(-0.6594)$ & $(0.5101)$ & 0.0030 & $(1.0247)$ & $(0.3067)$ & -0.0005 & $(-0.0983)$ & $(0.9223)$ & 0.0044 & $(1.0854)$ & $(0.2852)$ \\
\hline 17 & -0.0011 & $(-0$. & $(0.6733)$ & 0.0009 & $(0.3296)$ & $(0.7420)$ & 066 & 0) & $(0.2602)$ & 0.0005 & $(0.0765)$ & $(0.9394)$ \\
\hline 18 & 0.0010 & $(0.4924)$ & $(0.6228)$ & -0.0019 & $(-0.7239)$ & $(0.4699)$ & 0.0096 & $(1.4114)$ & $(0.1681)$ & $0.0111^{* * *}$ & $(2.8967)$ & $(0.0065)$ \\
\hline 19 & -0.0003 & $(-0$. & $(0.8948)$ & 0.0015 & $(0.6467)$ & 86) & 0034 & 29) & $(0.5843)$ & 0.0041 & (1.3214) & $(0.1949)$ \\
\hline 20 & 0.0006 & $(0.2754)$ & $(0.7832)$ & $-0.0057^{\star *}$ & $(-2.0719)$ & $(0.0395)$ & -0.0044 & $(-1.1215)$ & $(0.2707)$ & -0.0013 & $(-0.2071)$ & $(0.8371)$ \\
\hline 21 & 0.0014 & $(0.6617)$ & $(0.5087)$ & 0.0016 & $(0.5107)$ & $(0.6101)$ & -0.0043 & $(-1.0878)$ & $(0.2851)$ & 0.0016 & $(0.3836)$ & $(0.7036)$ \\
\hline 22 & -0.0005 & $(-0$ & $(0.7978)$ & -0.0025 & 72) & $(0.3868)$ & -0.0027 & 3806) & $(0.7061)$ & 0.0023 & $(0.3927)$ & $(0.6969)$ \\
\hline 23 & -0.0024 & $(-0.9010)$ & $(0.3683)$ & -0.0015 & $(-0.5816)$ & $(0.5615)$ & 0.0065 & (1.1912) & $(0.2426)$ & $-0.0100^{* *}$ & $(-2.0582)$ & $(0.0471)$ \\
\hline 24 & -0.0005 & $(-0$. & $(0.8304)$ & 0.0030 & $(0.8812)$ & $(0.3792)$ & -0.0031 & $(-0.4733)$ & $(0.6393)$ & -0.0026 & $(-0.5138)$ & $(0.6106)$ \\
\hline 25 & -0.0033 & $(-1.4077)$ & $(0.1602)$ & -0.0017 & $(-0.7616)$ & $(0.4472)$ & $0.0085^{\star}$ & 7464) & $(0.0906)$ & 0.0004 & $(0.0710)$ & $(0.9438)$ \\
\hline 26 & -0.0010 & $(-0.4463)$ & $(0.6557)$ & 0.0024 & $(0.8473)$ & $(0.3978)$ & 0.0004 & $(0.0822)$ & $(0.9350)$ & -0.0054 & $(-1.0355)$ & $(0.3075)$ \\
\hline 27 & -0.0009 & $(-0.3821)$ & $(0.7026)$ & .0033 & 1.2051) & $(0.2296)$ & -0.0086 & $(-1.5730)$ & $(0.1259)$ & 0.0061 & (1.0513) & $(0.3003)$ \\
\hline 28 & -0.0028 & $(-1.3896)$ & $(0.1656)$ & -0.0002 & $(-0.0795)$ & $(0.9367)$ & 0.0005 & $(0.0856)$ & $(0.9323)$ & -0.0044 & $(-0.7367)$ & $(0.4662)$ \\
\hline 29 & 0.0024 & $(0.9751)$ & $(0.3303)$ & -0.0032 & $(-1.1740)$ & $(0.2418)$ & 0.0141 & $(1.5911)$ & $(0.1217)$ & 0.0062 & $(1.2626)$ & $(0.2151)$ \\
\hline 30 & 0.0008 & $(0.3721)$ & $(0.7101)$ & -0.0030 & $(-1.1587)$ & $(0.2480)$ & 0.0010 & $(0.1851)$ & $(0.8543)$ & 0.0113 & $(0.9905)$ & $(0.3288)$ \\
\hline
\end{tabular}

Notes: ${ }^{\star}$ Denotes statistical significance at $10 \%$ levels; ${ }^{* *}$ Denotes statistical significance at $5 \%$ levels; ${ }^{* * \star}$ Denotes statistical significance at $1 \%$ levels.

Table 5. T test on subsample CAAR of the acquirers in different industries.

\begin{tabular}{|c|c|c|c|c|c|c|c|c|c|c|c|c|}
\hline & \multicolumn{3}{|c|}{ manufacturing } & \multicolumn{3}{|c|}{ service } & \multicolumn{3}{|c|}{ wholesale and retail } & \multicolumn{3}{|c|}{ natural resources } \\
\hline $\mathrm{N}$ & & 312 & & & 203 & & & 32 & & & 36 & \\
\hline windows & 1 & 2 & 3 & 1 & 2 & 3 & 1 & 2 & 3 & 1 & 2 & 3 \\
\hline mean & -0.0285 & -0.0135 & -0.0120 & -0.0014 & -0.0078 & -0.0081 & -0.0327 & -0.0032 & 0.0054 & 0.0269 & -0.0038 & -0.0039 \\
\hline p-statistics & $(0.2882)$ & $(0.3259)$ & $(0.2023)$ & $(0.9602)$ & $(0.6004)$ & $(0.4670)$ & $(0.6608)$ & $(0.9433)$ & $(0.8723)$ & $(0.6268)$ & $(0.9026)$ & $(0.8576)$ \\
\hline
\end{tabular}


level). This indicates that the natural resources stock market has made a negative reaction one day ahead of the announcement day. Similar to the service industry stock market, the natural resources stock market also has the phenomenon of early response to announcement information. The difference is that the natural resources stock market's early reflection of M\&A information is negative, while the service stock market is positive. What surprised us is that the wholesale and retail stock market seems to be insensitive to the information release of horizontal mergers and acquisitions. We don't find any statistical significant change in stock abnormal returns around the announcement day.

From Table 5, we find the CAAR of the acquirers in manufacturing industry lost a total of $2.85 \%, 1.35 \%$ and $1.20 \%$ of the stock returns in $(-30,+30),(-10$, $+10)$ and $(-5,+5)$, acquirers in service industry lost a total of $0.14 \%, 0.78 \%$ and $0.81 \%$ of the stock returns in $(-30,+30),(-10,+10)$ and $(-5,+5)$, acquirers in wholesale and retail industry lost a total of $3.27 \%$ and $0.32 \%$ of the stock returns in $(-30,+30),(-10,+10)$. We also notice that acquirers in wholesale and retail industry obtain a total of $0.54 \%$ of the stock abnormal returns in $(-5,+5)$. Unfortunately, this positive stock abnormal return is not statistically significantly different from zero. Through the analysis of the AAR and CAAR of the acquirers in different industries, we still do not found any evidence to support hypothesis 1.

Table 6 and Table 7 show the AAR and CAAR of the targets in different industries. From Table 6, we find the targets in manufacturing industry gain a total of $1.14 \%, 0.69 \%, 0.86 \%, 1.22 \%, 2.35 \%, 16.43 \%$ and $3.70 \%$ of the stock returns in $(-5,+1)$, which are significantly different from zero (under the condition of $1 \%$ of the significance level). This shows that the manufacturing stock market has already reacted a week or so ahead the horizontal merger announcement day, which is consistent with the conclusion of the whole sample. Compared with the full sample, the manufacturing stock markets perform better and achieve an abnormal return of $2.52 \%$ over the full sample. The targets in service industry gain a total of $0.66 \%, 0.83 \%, 0.78 \%, 0.69 \%, 1.49 \%, 10.93 \%$ and $1.74 \%$ of the stock returns in $(-5,+1)$, which are significantly different from zero. Compared with the full sample, the stock markets in service industry perform lower and achieve an abnormal return of $2.98 \%$ less than the full sample. Different from the conclusions of full sample, the manufacturing subsample, and the service subsample, targets in natural resources industry only achieve a statistically significant level of abnormal stock returns of $8.20 \%$ on announcement day. This shows that the impact of the M\&A announcement on the targets' stock price only appears on the announcement day, and the natural resources stock market did not appear to react in advance. Targets in wholesale and retail industry gain a total of $1.97 \%, 2.66 \%$ and $14.09 \%$ of the stock returns in $(-2,0)$, which are significantly different from zero. This shows that the impact of the M\&A announcement on the wholesale and retail stock price is particularly concentrate from 2 days before the announcement day to the announcement day. The wholesale and retail stock market has already responded about 2 days before the 
Table 6. T test on subsample AAR of the targets in different industries.

\begin{tabular}{|c|c|c|c|c|c|c|c|c|c|c|c|c|}
\hline \multirow{2}{*}{$\mathrm{t}$} & \multicolumn{3}{|c|}{ manufacturing } & \multicolumn{3}{|c|}{ service } & \multicolumn{3}{|c|}{ wholesale and retail } & \multicolumn{3}{|c|}{ natural resources } \\
\hline & mean & t-statistics & p-statistics & mean & t-statistics & p-statistics & mean & t-statistics & p-statistics & mean & t-statistics & p-statistics \\
\hline-30 & 0.0028 & (1.1310) & $(0.2588)$ & $0.0063^{* *}$ & $(2.1788)$ & $(0.0302)$ & $-0.0186^{* * *}$ & $(-2.7762)$ & $(0.0086)$ & 0.0004 & $(0.0551)$ & $(0.9564)$ \\
\hline-29 & -0.0038 & $(-1.5727)$ & $(0.1166)$ & -0.0042 & $(-1.6029)$ & $(0.1102)$ & $-0.0082^{* *}$ & $(-2.0374)$ & $(0.0488)$ & -0.0055 & $(-0.5942)$ & $(0.5559)$ \\
\hline-28 & -0.0024 & $(-0.8491)$ & $(0.3964)$ & 0.0002 & $(0.0652)$ & $(0.9480)$ & -0.0110 & $(-1.3604)$ & $(0.1819)$ & -0.0186 & $(-1.3814)$ & $(0.1752)$ \\
\hline-27 & $0.0073^{* * *}$ & $(2.6028)$ & $(0.0096)$ & -0.0002 & $(-0.0922)$ & $(0.9266)$ & -0.0048 & $(-0.5399)$ & $(0.5925)$ & $-0.0200^{* *}$ & $(-2.1095)$ & $(0.0415)$ \\
\hline-26 & 0.0030 & $(0.8813)$ & $(0.3787)$ & 0.0015 & $(0.6586)$ & $(0.5108)$ & 0.0043 & $(0.5049)$ & $(0.6166)$ & 0.0080 & $(0.8202)$ & $(0.4172)$ \\
\hline-25 & 0.0000 & $(0.0168)$ & $(0.9866)$ & 0.0043 & $(1.5212)$ & $(0.1294)$ & 0.0035 & $(0.3473)$ & $(0.7304)$ & 0.0046 & $(0.5188)$ & $(0.6069)$ \\
\hline-24 & -0.0002 & $(-0.0918)$ & $(0.9269)$ & 0.0025 & $(0.9355)$ & $(0.3504)$ & -0.0010 & $(-0.0892)$ & $(0.9294)$ & -0.0118 & $(-1.3479)$ & $(0.1857)$ \\
\hline-23 & 0.0021 & $(0.7800)$ & $(0.4359)$ & -0.0005 & $(-0.2294)$ & $(0.8187)$ & 0.0174 & $(1.2750)$ & $(0.2103)$ & -0.0071 & $(-0.7756)$ & $(0.4428)$ \\
\hline-22 & 0.0029 & (1.1105) & $(0.2675)$ & -0.0034 & $(-1.4219)$ & $(0.1563)$ & 0.0040 & $(0.7991)$ & $(0.4293)$ & -0.0042 & $(-0.7497)$ & $(0.4580)$ \\
\hline-21 & 0.0000 & $(0.0091)$ & $(0.9927)$ & 0.0001 & $(0.0222)$ & $(0.9823)$ & -0.0055 & $(-0.9466)$ & $(0.3500)$ & $0.0110^{*}$ & $(1.8804)$ & $(0.0677)$ \\
\hline-20 & -0.0025 & $(-0.8474)$ & $(0.3973)$ & -0.0015 & $(-0.5915)$ & $(0.5547)$ & 0.0129 & $(1.3766)$ & $(0.1769)$ & -0.0049 & $(-0.7938)$ & $(0.4322)$ \\
\hline-19 & 0.0043 & $(1.5266)$ & $(0.1277)$ & 0.0009 & $(0.2649)$ & $(0.7913)$ & -0.0049 & $(-0.6249)$ & $(0.5359)$ & 0.0111 & $(1.6566)$ & $(0.1058)$ \\
\hline-18 & -0.0001 & $(-0.0182)$ & $(0.9855)$ & $0.0044^{*}$ & $(1.7683)$ & $(0.0782)$ & -0.0007 & $(-0.0930)$ & $(0.9264)$ & -0.0028 & $(-0.2821)$ & $(0.7794)$ \\
\hline-17 & -0.0020 & $(-0.7900)$ & $(0.4300)$ & $-0.0043^{*}$ & $(-1.6972)$ & $(0.0909)$ & -0.0043 & $(-0.6581)$ & $(0.5145)$ & -0.0028 & $(-0.2411)$ & $(0.8108)$ \\
\hline-16 & $0.0071^{* * *}$ & $(2.8536)$ & $(0.0046)$ & 0.0023 & $(0.7828)$ & $(0.4344)$ & 0.0020 & $(0.3501)$ & $(0.7283)$ & 0.0046 & $(0.8002)$ & $(0.4286)$ \\
\hline-15 & -0.0021 & $(-0.8954)$ & $(0.3711)$ & $0.0043^{*}$ & (1.6714) & $(0.0958)$ & 0.0002 & $(0.0414)$ & $(0.9672)$ & 0.0125 & $(0.9531)$ & $(0.3466)$ \\
\hline-14 & 0.0040 & $(0.9495)$ & $(0.3429)$ & 0.0030 & $(0.9731)$ & $(0.3314)$ & 0.0118 & $(1.5352)$ & $(0.1332)$ & -0.0030 & $(-0.5609)$ & $(0.5782)$ \\
\hline-13 & -0.0015 & $(-0.6061)$ & $(0.5448)$ & 0.0055 & $(1.3559)$ & $(0.1763)$ & 0.0108 & (1.0918) & $(0.2820)$ & 0.0022 & $(0.3842)$ & $(0.7030)$ \\
\hline-12 & $0.0046^{*}$ & $(1.8785)$ & $(0.0611)$ & 0.0016 & $(0.6164)$ & $(0.5382)$ & 0.0023 & $(0.3457)$ & $(0.7316)$ & 0.0048 & $(1.1614)$ & $(0.2527)$ \\
\hline-11 & $0.0069^{*}$ & $(1.9652)$ & $(0.0501)$ & 0.0030 & (1.1902) & $(0.2351)$ & $0.0116^{*}$ & (1.8380) & $(0.0741)$ & 0.0016 & $(0.2952)$ & $(0.7694)$ \\
\hline-10 & 0.0029 & $(0.9929)$ & $(0.3214)$ & 0.0015 & $(0.6620)$ & $(0.5086)$ & 0.0153 & $(1.0909)$ & $(0.2824)$ & -0.0016 & $(-0.3871)$ & $(0.7009)$ \\
\hline-9 & 0.0036 & $(1.1893)$ & $(0.2351)$ & 0.0002 & $(0.0604)$ & $(0.9519)$ & -0.0080 & $(-1.1540)$ & $(0.2559)$ & 0.0000 & $(0.0028)$ & $(0.9978)$ \\
\hline-8 & $0.0080^{* * *}$ & $(2.6514)$ & $(0.0083)$ & 0.0033 & $(1.2606)$ & $(0.2086)$ & 0.0058 & (1.0970) & $(0.2797)$ & 0.0002 & $(0.0398)$ & $(0.9685)$ \\
\hline-7 & 0.0038 & $(1.4788)$ & $(0.1400)$ & 0.0031 & $(1.1630)$ & $(0.2459)$ & 0.0110 & $(1.4749)$ & $(0.1487)$ & -0.0039 & $(-0.5708)$ & $(0.5715)$ \\
\hline-6 & 0.0047 & $(1.6287)$ & $(0.1042)$ & 0.0014 & $(0.5102)$ & $(0.6104)$ & -0.0036 & $(-0.4907)$ & $(0.6265)$ & 0.0090 & $(1.3025)$ & $(0.2006)$ \\
\hline-5 & $0.0114^{* * *}$ & $(4.0819)$ & $(0.0001)$ & $0.0066^{*}$ & $(1.8834)$ & $(0.0608)$ & 0.0006 & $(0.0807)$ & $(0.9361)$ & 0.0000 & $(0.0048)$ & $(0.9962)$ \\
\hline-4 & $0.0069^{* *}$ & $(2.5134)$ & $(0.0124)$ & $0.0083^{* * *}$ & $(3.1128)$ & $(0.0021)$ & 0.0084 & $(1.5665)$ & $(0.1258)$ & 0.0016 & $(0.2785)$ & $(0.7821)$ \\
\hline-3 & $0.0086^{* * *}$ & (2.9864) & $(0.0030)$ & $0.0078^{\star *}$ & $(2.4775)$ & $(0.0139)$ & 0.0096 & (1.0778) & $(0.2881)$ & -0.0021 & $(-0.3056)$ & $(0.7616)$ \\
\hline-2 & $0.0122^{* * *}$ & $(3.9241)$ & $(0.0001)$ & $0.0069^{* *}$ & $(2.1961)$ & $(0.0290)$ & $0.0197^{* *}$ & $(2.3544)$ & $(0.0240)$ & 0.0066 & $(1.0033)$ & $(0.3221)$ \\
\hline-1 & $0.0235^{* * *}$ & $(6.3705)$ & $(0.0000)$ & $0.0149^{* * *}$ & $(4.1262)$ & $(0.0000)$ & $0.0266^{* *}$ & $(2.2648)$ & $(0.0295)$ & -0.0063 & $(-0.6239)$ & $(0.5364)$ \\
\hline 0 & $0.1643^{* * *}$ & $(12.9540)$ & $(0.0000)$ & $0.1093^{* * *}$ & $(10.7572)$ & $(0.0000)$ & $0.1409^{* * *}$ & $(4.1239)$ & $(0.0002)$ & $0.0820^{* * *}$ & (3.6075) & $(0.0009)$ \\
\hline 1 & $0.0370^{* * *}$ & $(4.7043)$ & $(0.0000)$ & $0.0174^{* * *}$ & (3.2828) & $(0.0012)$ & 0.0119 & $(0.7287)$ & $(0.4708)$ & 0.0209 & $(1.1041)$ & $(0.2765)$ \\
\hline 2 & $-0.0039 * *$ & $(-2.1151)$ & $(0.0350)$ & -0.0000 & $(-0.0200)$ & $(0.9840)$ & -0.0032 & $(-0.8685)$ & $(0.3907)$ & 0.0118 & $(1.4018)$ & $(0.1691)$ \\
\hline 3 & 0.0001 & $(0.0379)$ & $(0.9698)$ & 0.0021 & $(1.0258)$ & $(0.3059)$ & -0.0001 & $(-0.0375)$ & $(0.9703)$ & -0.0008 & $(-0.0911)$ & $(0.9279)$ \\
\hline 4 & -0.0025 & $(-1.2866)$ & $(0.1990)$ & -0.0023 & $(-1.2812)$ & $(0.2013)$ & 0.0008 & $(0.2004)$ & $(0.8423)$ & $-0.0101^{* *}$ & $(-2.3482)$ & $(0.0242)$ \\
\hline
\end{tabular}




\section{Continued}

\begin{tabular}{|c|c|c|c|c|c|c|c|c|c|c|c|c|}
\hline 5 & 0.0043 & $(0.9341)$ & $(0.3508)$ & $-0.0029^{*}$ & $(-1.6846)$ & $(0.0933)$ & -0.0018 & $(-0.4851)$ & $(0.6305)$ & 0.0026 & $(0.4982)$ & $(0.6212)$ \\
\hline 6 & -0.0021 & 888) & $(0.2353)$ & -0.0023 & 531) & .2113) & .0020 & $.4900)$ & $(0.6271)$ & -0.0109 & 5516) & $0.1290)$ \\
\hline 7 & 0.0013 & $(0.6880)$ & $(0.4919)$ & 0.0002 & $(0.0887)$ & $(0.9294)$ & 0.0008 & $.2135)$ & $(0.8321)$ & 0.0113 & $(1.0934)$ & $0.2811)$ \\
\hline 8 & -0.0000 & $(-0.0054)$ & .9957) & 0.0020 & .0255) & $(0.3061)$ & 0.0037 & $.1485)$ & $(0.2582)$ & 0.0103 & $0.7816)$ & $.4393)$ \\
\hline 9 & 0.0013 & $(0.8268)$ & $(0.4088)$ & -0.0011 & $(-0.5419)$ & $(0.5883)$ & -0.0020 & $(-0.5371)$ & $(0.5944)$ & -0.0095 & $(-1.1289)$ & $0.2660)$ \\
\hline 10 & -0.0010 & $(-0.5033)$ & $(0.6151)$ & -0.0020 & $1.3102)$ & $(0.1913)$ & 0.0019 & $.4084)$ & $(0.6853)$ & -0.0063 & $(-0.7313)$ & $0.4691)$ \\
\hline 11 & $0.0036^{* *}$ & $(-2.2895)$ & $(0.0226)$ & 0.0012 & $(0.7662)$ & $(0.4443)$ & -0.0048 & 876) & $(0.2059)$ & 0.0019 & $0.4217)$ & $0.6757)$ \\
\hline 12 & -0.0001 & $(-0.0521)$ & $(0.9585)$ & -0.0027 & $(-1.3796)$ & $(0.1689)$ & 0.0024 & .6319) & $(0.5313)$ & 0.0004 & $0.0585)$ & 0.9537) \\
\hline 13 & 0.0011 & $(0.6731)$ & $0.5013)$ & 0.0002 & .1154) & $.9082)$ & 0.0020 & $.6796)$ & $(0.5010)$ & 0.0038 & $(0.7315)$ & $0.4689)$ \\
\hline 14 & $-0.0028^{*}$ & $(-1.8224)$ & $0.0692)$ & -0.0014 & 986) & $(0.5499$ & 0.0002 & 2) & .97 & .0001 & .0104) & $0.9918)$ \\
\hline 15 & -0.0011 & $(-0.5254)$ & $(0.5996)$ & -0.0008 & $-0.4492)$ & $(0.6537)$ & .0034 & 938) & $(0.5563)$ & -0.0034 & $(-0.2980)$ & $0.7673)$ \\
\hline 16 & -0.0025 & $(-1.5386)$ & $0.1247)$ & -0.0001 & 353) & .9719) & -0.0036 & 777) & .176 & 0129 & 2312) & $.2258)$ \\
\hline 17 & 0.0004 & 1635) & $.8702)$ & 0.0005 & 824) & .777 & 0009 & 62) & .76 & .0222 & 8571) & ..3967) \\
\hline 18 & -0.0024 & 164) & $.1302)$ & 0.0005 & 6) & .796 & 32 & 9) & ) & 1 & 29) & $.1437)$ \\
\hline 19 & $0.0048^{\star *}$ & $(2.3327)$ & $0.0202)$ & -0.0031 & 517) & .1196 & 0.0010 & 3) & (0.7408) & .0024 & 3040) & $0.7628)$ \\
\hline 20 & 0.0003 & $(0.1562)$ & $.8759)$ & -0.0025 & 4733) & .1419 & .0100 & 594) & 1055) & 0.0044 & 642) & $.4495)$ \\
\hline 21 & -0.0010 & 1) & .564 & 0000 & $.0192)$ & .98 & 045 & & & -0.6 & 404) & $0.3529)$ \\
\hline 22 & 0.0006 & $(0.3611)$ & $(0.7182)$ & 0.0014 & $-0.6167)$ & .538 & 003 & ) & 4) & $0 .($ & 0747) & $0.0039)$ \\
\hline 23 & 0.0002 & 202 & 8996) & -0.0020 & 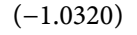 & 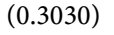 & 0055 & 17. & ) & -0.0073 & 4712) & 0.1493 \\
\hline 24 & 0.0010 & 5251) & .5998） & 0003 & 911) & .8 & .0043 & 17) & 410) & $117^{\star *}$ & 2.3818) & $0.0223)$ \\
\hline 25 & $-0.0042^{\star *}$ & $(-2.2066)$ & $(0.0279)$ & $-0.0033^{*}$ & 7516) & $(0.0810)$ & $0062^{*}$ & 978) & $(0.0979)$ & $-0.0139^{*}$ & .7933) & $(0.0809)$ \\
\hline 26 & 0.0009 & (0.4945) & $(0.6213)$ & -0.0012 & 6338) & .5268 & 0.0045 & 080) & .1989) & .0036 & $.4074)$ & $0.6860)$ \\
\hline 27 & 0.0006 & $(0.3313)$ & $(0.7406)$ & -0.0006 & $(-0.2818)$ & $(0.7783)$ & -0.0028 & $(-0.6697)$ & $(0.5072)$ & -0.0046 & 0982) & $(0.2790)$ \\
\hline 28 & -0.0006 & $(-0.3308)$ & $(0.7409)$ & -0.0016 & 8432) & $(0.399$ & -0.0070 & 111) & $(0.1393)$ & 0.0018 & $(0.3754)$ & $(0.7095)$ \\
\hline 29 & 0.0019 & (1.1717) & $(0.2420)$ & 0.0004 & 2377） & $(0.8123)$ & .0005 & .1261) & $(0.9003)$ & 0.0055 & $(1.1572)$ & $(0.2544)$ \\
\hline 30 & 0.0008 & $(0.4288)$ & $(0.6683)$ & 0026 & .1647) & $(0.2452)$ & .0000 & $(0.0047)$ & $(0.9963)$ & -0.0027 & $(-0.3815)$ & $(0.7050)$ \\
\hline
\end{tabular}

Notes: ${ }^{\star}$ Denotes statistical significance at $10 \%$ levels; ${ }^{\star \star}$ Denotes statistical significance at $5 \%$ levels; ${ }^{\star \star \star}$ Denotes statistical significance at $1 \%$ levels.

Table 7. T test on subsample CAAR of the targets in different industries.

\begin{tabular}{|c|c|c|c|c|c|c|c|c|c|c|c|c|}
\hline & \multicolumn{3}{|c|}{ manufacturing } & \multicolumn{3}{|c|}{ service } & \multicolumn{3}{|c|}{ wholesale and retail } & \multicolumn{3}{|c|}{ natural resources } \\
\hline $\mathrm{N}$ & & 312 & & & 203 & & & 32 & & & 36 & \\
\hline windows & 1 & 2 & 3 & 1 & 2 & 3 & 1 & 2 & 3 & 1 & 2 & 3 \\
\hline mean & $0.3092^{* * *}$ & $0.2844^{* * *}$ & $0.2619^{* * *}$ & $0.1840^{* * *}$ & $0.1743^{* * *}$ & $0.1682^{* * *}$ & $0.2252^{* * *}$ & $0.2405^{* * *}$ & $0.2136^{* * *}$ & $0.1445^{\star *}$ & $0.1049^{* * *}$ & $0.1068^{* * *}$ \\
\hline t-statistics & $(13.8258)$ & $(18.1753)$ & $(18.3555)$ & $(8.3712)$ & $(12.1562)$ & $(13.5146)$ & $(3.0059)$ & $(5.3433)$ & $(4.4905)$ & $(2.5809)$ & $(2.7929)$ & $(3.8498)$ \\
\hline p-statistics & $(0.0000)$ & $(0.0000)$ & $(0.0000)$ & $(0.0000)$ & $(0.0000)$ & $(0.0000)$ & $(0.0047)$ & $(0.0000)$ & $(0.0001)$ & $(0.0138)$ & $(0.0081)$ & $(0.0004)$ \\
\hline
\end{tabular}

Notes: ${ }^{*}$ Denotes statistical significance at $10 \%$ levels; ${ }^{* *}$ Denotes statistical significance at $5 \%$ levels; ${ }^{* * *}$ Denotes statistical significance at $1 \%$ levels. 
announcement day, while the manufacturing stock market and service stock market respond about 5 days ahead.

From Table 7, we find the CAAR of the targets in manufacturing industry gain a total of $30.92 \%, 28.44 \%$ and $26.19 \%$ of the stock returns in $(-30,+30)$, $(-10,+10)$ and $(-5,+5)$, targets in service industry gain a total of $18.40 \%$, $17.43 \%$ and $16.82 \%$ of the stock returns in $(-30,+30),(-10,+10)$ and $(-5,+5)$, targets in wholesale and retail industry gain a total of $22.52 \%, 24.05 \%$ and $21.36 \%$ of the stock returns in $(-30,+30),(-10,+10)$ and $(-5,+5)$, targets in natural resources industry gain a total of $14.45 \%, 10.49 \%$ and $10.68 \%$ of the stock returns in $(-30,+30),(-10,+10)$ and $(-5,+5)$. All these positive reactions are statistically significantly different from zero (under the condition of $1 \%$ of the significance level). Through the analysis of the AAR and CAAR of the targets in different industries, hypothesis 2 is further verified.

\section{Summary of Findings and Directions for Further Research}

This paper bridges the theoretical work in horizontal mergers and acquisitions with the empirical work in corporate finance. We use event-study method to investigate the short-term performance of horizontal mergers and acquisitions. By collecting the horizontal mergers and acquisitions of listed companies in the United States from SDC database and the daily earnings data of US listed companies from CRSP database, this paper find that the targets obtain positive stock return after announcement while the acquirers obtain negative stock return. In the short term, the shareholder wealth of the targets is enhanced. Our research support hypothesis 2 but does not support hypothesis 1 . We also find that The US stock market has already responded positively about a week before the horizontal merger announcement day. The possible reason is that the information disclosure is not standardized or the supervision means are not in place. Through observations of different industries, this paper find that horizontal mergers and acquisitions have the most obvious impact on the shareholder wealth of the targets in the manufacturing and wholesale and retail industries.

We also find that the impact of the horizontal M\&A on the acquirers' stock return only work on the announcement day, on which the acquirers obtain negative stock return and acquirers' shareholder wealth suffer losses. In fact, previous scholars have similar conclusions on acquirers' short-term M\&A performance. Xin Zhang [24] use event-study method to analyze whether the 1216 M\&A events of Chinese listed companies from 1993 to 2002 creat shareholder value. The empirical results show that the stock premium of the acquirers is $-16.76 \%$ after the merger and the stock price of the acquirers show a downward trend. The study of Shahrur [16] also points out the acquirers obtain a negative abnormal stock return of $-0.61 \%$ at the window $(-1,0)$. Bruner [25] review more than 130 classic M\&A research literatures from 1971 to 2001. Through the summary of the research findings, the authors find that the shareholder's wealth of targets in the mature stock market is much higher than that of the acquirers. 
The stock return rate of the acquirers has a negative tendency.

What causes the acquirers' shareholder wealth loss after horizontal merger? Principal-agent theory gives a possible explanation. Horizontal M\&A occur not because of the consideration of shareholder wealth, but because managers are maximizing their own interests. Jensen [26] points out that managers can increase the size of firms through mergers and acquisitions to control more free cash flow, and accordingly have more on-the-job consumption and management power. Berkovitch\&Narayanan [17] also point out that when selecting the M\&A target, managers may select companies that can enhance the company's dependence on their individual management skills, although such acquisitions may reduce the company's value. It is bound to damage the shareholder wealth of the acquirers. Another possible explanation is that mergers occur because of the management's overly optimistic valuation of the targets and the false expectations of synergies. This leads to an increase in the targets' shareholder wealth at the expense of the decline in acquirers' shareholder wealth [24].

Our research has the following limitations. First, in order to explore the M\&A performance differences in the industry, we collect data from manufacturing, wholesale, natural resources and retail trade and service. We don't have access to data from other industries. Second, our research explores the short-term performance of horizontal mergers, but does not further study the factors that affect the short-term performance of horizontal mergers and acquisitions.

Follow-up studies may improve the findings in two directions. First, focusing on horizontal mergers and acquisitions outside the US as M\&A transactions occur frequently around the world. According to Thomson Reuters database, the scale of global M\&A transactions in 2015 has reached 3.90 trillion US dollars. In 2016, the global M\&A transaction volume reached 3.10 trillion US dollars. In 2017, the total global M\&A transactions reached 3.50 Trillions of dollars. With the development of the global capital market, the information disclosure of the stock market will be more standardized. It is feasible to use event-study method to analyze horizontal mergers and acquisitions performance outside the United States.

Second, further exploring the factors that affect horizontal M\&A performance? Mengcheng Lu [27] reviews the research on the influencing factors of horizontal M\&A performance. Many scholars focus on the characteristics of M\&A transactions such as payment methods [28] [29], related transactions [30] [31]. Subsequent research can collect more data reflecting the characteristics of both sides of the M\&A transaction, and further explore the factors that affect the performance of horizontal M\&A.

\section{Conflicts of Interest}

The author declares no conflicts of interest regarding the publication of this paper. 


\section{References}

[1] Xu, Z. and Wang, Y. (2016) The Impact of Horizontal Mergers and Acquisitions on the Structure of China's Real Estate Market. Journal of Shandong University of Finance and Economics, No. 1, 39-47.

[2] Cömez-Dolgan, N. and Tanyeri, B. (2015) Inventory Performance with Pooling: Evidence from Mergers and Acquisitions. International Journal of Production Economics, 168, 331-339. https://doi.org/10.1016/j.ijpe.2015.06.003

[3] Li, W. and Ning, X. (2018) Synergistic Analysis of Horizontal M\&A of Startups-Taking Didi's Trip to Buy Uber China as an Example. Economic and Trade Practice, No. 13, 228-229.

[4] Marks, M.L. and Mirvis, P.H. (2001) Making Mergers and Acquisitions Work: Strategic and Psychological Preparation. The Academy of Management Executive, 15, 80 .

[5] Chen, Y. and Li, Q. (2008) Analysis of Production Synergies in Horizontal Mergers. National Business (Economic Theory Research), No. 11, 60-62.

[6] Yu, G. and Tang, G. (2000) Motivation Model and Defensive Motivation Hypothesis of Enterprise Mergers and Acquisitions. Quantitative Economics and Economics Research, No. 9, 35-38.

[7] Shaver, J.M. (2006) A Paradox of Synergy: Contagion and Capacity Effects in Mergers and Acquisitions. The Academy of Management Review, 962-976. https://doi.org/10.5465/amr.2006.22527468

[8] Xu, H. and Lin, Z. (2015) Product Market Competition, Asset Specificity and Horizontal Mergers and Acquisitions of Listed Companies. Nankai Management Review, No. 3, 48-59.

[9] Deneckere, R. and Davidson, C. (1985) Incentives to Form Coalitions with Bertrand Competition. The RAND Journal of Economics, 16, 473-486. https://doi.org/10.2307/2555507

[10] Fan, X. and Han, Y. (2012) Empirical Research on the Effect of Horizontal Mergers and Acquisitions of Retail Enterprises in China-Based on the Research of Data of Listed Companies. Business Economy and Management, No. 7, 14-20.

[11] Inderst, R. and Shaffer, G. (2007) Retail Mergers, Buyer Power and Product Variety. The Economic Journal, 117, 45-67.

[12] Xu, X. (2015) Short-Term Performance Study of M\&A in Chinese Listed Companies-Based on Industry Similarity of M\&A. Contemporary Economic Science, No. 3, 89-98.

[13] Duso, T., Gugler, K. and Yurtoglu, B. (2010) Is the Event Study Methodology Useful for Merger Analysis? A Comparison of Stock Market and Accounting Data. International Review of Law and Economics, 30, 186-192. https://doi.org/10.1016/j.irle.2010.02.001

[14] Wårell, L. (2007) A Horizontal Merger in the Iron Ore Industry: An Event Study Approach. Resources Policy, 32, 191-204. https://doi.org/10.1016/j.resourpol.2007.08.006

[15] Eckbo, B.E. (1983) Horizontal Mergers, Collusion, and Stockholder Wealth. Journal of Financial Economics, 11, 241-273. https://doi.org/10.1016/0304-405X(83)90013-2

[16] Shahrur, H. (2005) Industry Structure and Horizontal Takeovers: Analysis of Wealth Effects on Rivals, Suppliers, and Corporate Customers. Journal of Financial Economics, 76, 61-98. https://doi.org/10.1016/j.jfineco.2004.01.001 
[17] Berkovitch, E. and Narayanan, M.P. (1993) Motives for Takeovers: An Empirical Investigation. Journal of Financial and Quantitative Analysis, 28, 347-362. https://doi.org/10.2307/2331418

[18] Wan, X. and Liang, T. (2016) Research on the Influence of Enterprise M\&A on Shareholders' Wealth Effect. Price Theory and Practice, No. 9, 132-135.

[19] Wurgler, J. (2000) Financial Markets and the Allocation of Capital. Journal of Financial Economics, 58, 187. https://doi.org/10.1016/S0304-405X(00)00070-2

[20] Fama, E.F. (1970) Efficient Capital Markets: A Review of Theory and Empirical Work. The Journal of Finance, 25, 383-417. https://doi.org/10.2307/2325486

[21] Box, G.E.P. and Pierce, D.A. (1970) Distribution of Residual Autocorrelations in Autoregressive-Integrated Moving Average Time Series Models. Journal of the American Statistical Association, 65, 1509-1526. https://doi.org/10.1080/01621459.1970.10481180

[22] Liu, W. and Yang, Z. (2007) A Summary of Research on the Efficiency of Securities Market. Legal System and Economy (Second Half of the Month), No. 9, 80-81.

[23] Zhao, W. and Yang, D. (2008) Characteristics and Evidence of Securities Market Efficiency: A Literature Review. Reform, No. 6, 130-135.

[24] Zhang, X. (2003) Does M\&A and Restructuring Create Value?-Theory and Empirical Study of China's Securities Market. Economic Research, No. 6, 20-29.

[25] Bruner, R.F. (2002) Does M\&A Pay a Survey of Evidence for the Decision-Maker. Journal of Applied Finance, 12, 48.

[26] Jensen, M.C. (1986) Agency Costs of Free Cash Flow, Corporate Finance, and Takeovers. The American Economic Review, 76, 323-329.

[27] Lu, M. (2018) A Literature Review of Research on Factors Affecting Cross-Border M\&A Performance. Market Weekly, No. 11, 26-28.

[28] He, Y. and Tang, F. (2018) Research on the Influence of M\&A Payment Methods on Enterprise Performance. Modern Commerce, No. 20, 125-127.

[29] Wei, W. (2018) The Impact of Different Payment Methods on the Long-Term Performance of Listed Companies' M\&A. Business Accounting, No. 14, 37-40.

[30] Han, S. (2016) Related M\&A, Payment Methods and M\&A Performance. Finance and Finance, No. 4, 71-77.

[31] Wang, Y., Tian, G. and Han, J. (2017) M\&A Performance Research of Linked M\&A-Based on Cash Flow Perspective. Economic Issues, No. 5, 110-116. 